\title{
Development of a Conceptual Model for Accelerated Project Prioritization after Disaster Event
}

\author{
Claudia Martins ${ }^{1}$, Laleh Ghanbari ${ }^{2}$, Chao Wang ${ }^{2, *}$, and Fernando Moreu ${ }^{1}$ \\ ${ }^{1}$ Department of Civil, Construction \& Environmental Engineering, The University of New Mexico, Albuquerque, NM 87131 \\ ${ }^{2}$ Bert S. Turner Department of Construction Management, Louisiana State University, Baton Rouge, LA 70803
}

\begin{abstract}
There is a need for rapid and responsive infrastructure repair and construction after natural disaster events such as hurricanes, wildfires, and tornadoes. These natural disasters often shut down basic infrastructure systems, including roads, bridges, water supply, and power supply, as experienced recently in several Region 6 states as well as in other states around the country. Accelerated construction practices are often used in these situations to speed up the traditional, and often slow, project delivery process. However, after a natural disaster, several and different types of transportation infrastructure components are in need of inspection, rehabilitation or reconstruction, and transportation agencies are challenged with the task of prioritizing these accelerated projects. This paper studied the current practices and institutional barriers to identify the critical decision criteria and to develop a conceptual model for prioritizing needs for accelerated construction after disaster events, specifically hurricanes and flooding which commonly affect Region 6.
\end{abstract}

\section{Introduction}

Transportation infrastructure has been severely affected by recent hurricanes and flooding, for example, after historic flooding in the state of Louisiana in 2016, the Louisiana Department of Transportation and Development reported the closure of approximately 200 roads, including more than 30 washouts of state highways [1]. Another 1,400 critical bridges needed to be inspected before they could be opened to traffic. Harvey floodwaters in Houston, TX collapsed bridges and also washed away roads by eroding their foundations. Highway traffic was disrupted by severe and prolonged inundation. Accelerated construction practices are often used in these situations to speed up the traditional, and often slow, project delivery process. However, after a natural disaster, several and different types of transportation infrastructure components requires inspection, rehabilitation or reconstruction, and transportation agencies be challenged with the task of prioritizing which projects should be tackled first considering resource constraints. The lack of a plan for accelerated transportation projects in response to disaster events increases the recovery time of the transportation network. Consequently, not only the efficiency of disaster response operations is affected, but also the reestablishment of the local economy is delayed. Malfunctioning infrastructure might also impose additional safety issues to the community exposed to disaster-induced safety hazards (e.g., a collapsed bridge, lack of traffic lights, dangerous routes, etc.) that could result in accidents and fatalities. In this study, a conceptual prioritization model for prioritizing needs for accelerated construction after natural disaster events is developed. The proposed framework for this research project is shown in Figure 1. The scope of this present study includes the phases of literature review and the conceptual prioritization model. The following phases of the research will be covered in future publications.

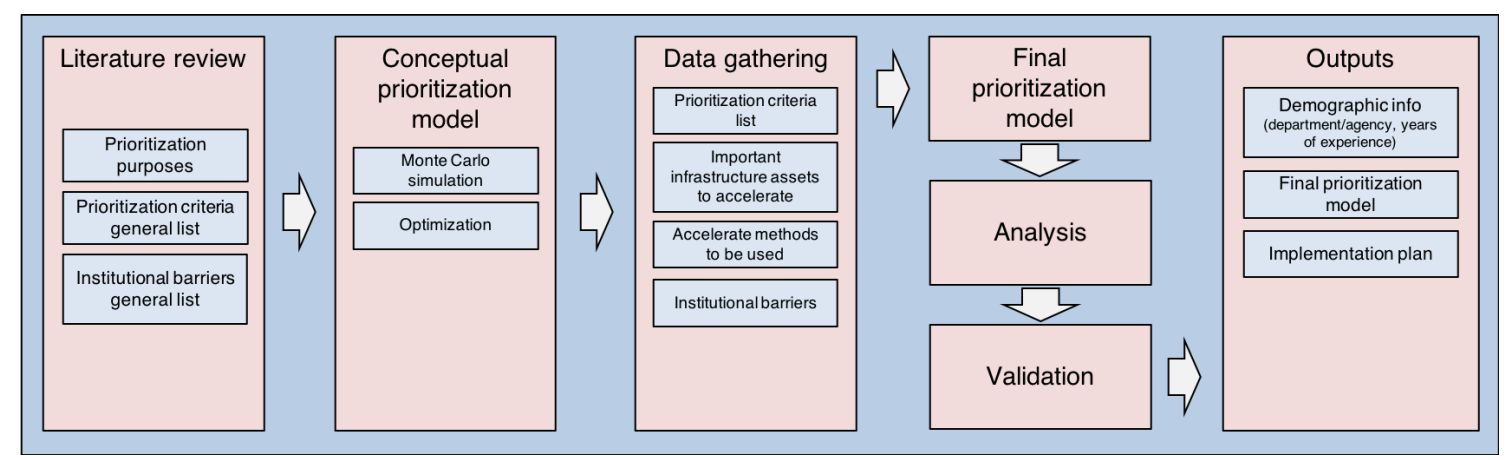

Fig. 1. Research framework.

\footnotetext{
* Corresponding author: chaowang@1su.edu
} 


\section{Literature review}

Many studies have been performed on prioritization techniques for reconstruction after natural disasters. Stein et al. [2] surveyed U.S. State Department of Transportation and Canadian provincial transportation agencies to investigate the current practices used by those agencies to prioritize the investment for LowVolume Roads (LVR). What they found was that the prioritization process usually starts with a combination of engineering data and analysis grouped by pavement and bridge management systems. Chen and Tzeng [3] presented an optimal fuzzy multi-objective model to assist with restoration decision for a post-quake road network by utilizing the concept of Network Restoration Problem (NRP) and Genetic Algorithm (GA). The authors addressed an asymmetric traffic assignment technique as a measurement tool for the effectiveness of this restoration schedule. The proposed model used a bilevel solution to prioritize the reconstruction of the assets. Zamanifar and Seyedhosseini [4] developed a Fuzzy VIKOR technique to deal with problem-related to ranking roadway reconstructions after a disaster.

The solution to prioritize the reconstruction of transportation networks after a disaster in an optimized way was developed in three studies by a similar group of authors. First, Orabi et al. [5] developed an equilibrium algorithm to evaluate the functionality of transportation networks after a disaster. Later, El-Anwar et al. [6] addressed an optimization-based solution of reconstruction plans for damaged transportation networks in the post-disaster period. Last, El-Anwar et al. [7] proposed a model to optimize plans of retrofitting damaged transportation networks after a disaster using Mixed Integer Linear Programming. Prioritization models are also applied for decision-making of road or infrastructure maintenance. In this case, the solutions are applied without the consideration of a disaster. Orugbo et al. [8] developed a model using integration of Analytical Hierarchy Process and Reliability Centered Maintenance to produce a prioritization plan of roadways recovery. The reliability logic and its associated risk numbers were utilized to categorize failures of roads into four groups and reclassify them. AHP was also applied to analyze decision-making criteria, break down the road network prioritization plan into more manageable levels and deal with linguistic variables. Table 1 list the criteria used in this study to prioritize the maintenance. Arif et al. [9] proposed a decision-making framework for infrastructure maintenance by extending the traditional single criterion of physical condition to other parameters aiming to attain a better application of limited funds. The authors also did a review of previous existing frameworks and the criteria used in these frameworks. Table 1 lists the criteria used in this study. The framework was applied in a US DOT for a maintenance investment decision-making process for four bridges considering five years and after the generation of the portfolios, constraint application, and the benefit-to-cost ratio analysis, the best cost/benefit solution was chosen to be considered.
The literature shows that the prioritization for transportation construction projects has been applied for different categories such as Low-Volume Roads (LVR), road network maintenance, cross-modal projects, and rail projects. It has also been used by the State DOTs to plan the State and Government Transportation Programs; for instance, the Unified Transportation Program (UTP) and the Statewide Transportation Improvement Program (STIP). Application of prioritization can also be found in pre- and post-disaster conditions, such as road recovery after a natural disaster, optimization of post-disaster reconstruction of transportation networks, postearthquake restoration process with repair prioritization of highway network system, and bridge retrofit prioritization critical for active pre-disaster risk mitigation of road transportation networks. Even though the current body of knowledge has investigated accelerated construction and post-disaster project prioritization, there is a lack of evidence of existing literature overlapping between these themes at a programmatic level for post-disaster recovery. Prior studies have not focused on a diverse portfolio of projects and have mostly concentrated on projects with similar characteristics. When faced with multiple needs, it is often difficult to adequately prioritize projects, especially when there are resource shortages that limit the amount of work that can be done at any given time.

Even though the current body of knowledge has investigated accelerated construction and post-disaster project prioritization for transportation infrastructure, the studies do not overlap between accelerated construction, emergency operations, and prioritization of infrastructure projects at a programmatic level for post-disaster recovery. Also, prior studies have not focused on a diverse portfolio of projects and have mostly concentrated on projects with similar characteristics. There is a need for further research and guidance to assist state DOTs in identifying and prioritizing needs for accelerated construction after hazard events. In this study, a multi-criteria conceptual model for prioritizing accelerated construction needs after a natural disaster is developed. We evaluate strategies for accelerating construction in a cost-effective manner post-disaster considering identification and quantification and decision criteria for a program of critical transportation infrastructure projects.

\section{Conceptual prioritization model}

The conceptual prioritization model was developed with five questions in mind: 1) Why do we need to accelerate the construction projects after a hazard event? 2) How do we define the re-establishment of the condition of the affected place? 3) How do we define the "recovery index"? 4) What are the variables that influence the decision to accelerate a construction project? 5) What is the final objective of the strategy for prioritizing needs for accelerated construction?

The proposed structure for the conceptual prioritization model is shown in Figure 2. The model was developed considering four main block components: 
the projects' prioritization criteria, the accelerated methods available, the projects' alternatives, and the scheduling of the project alternatives.

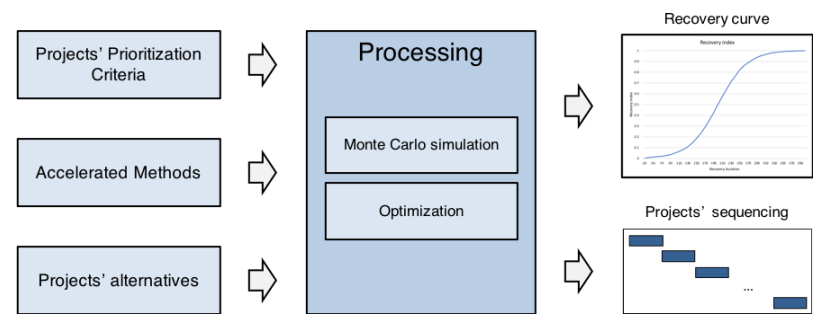

Fig. 2. Conceptual prioritization model diagram.

\subsection{Model inputs}

Three of the main block components comprise the inputs of the model: the projects' prioritization criteria, the accelerated methods, and the projects' alternatives. Moreover, each of these block components is also defined by a set of variables that are part of the model formulation. The projects' prioritization criteria component considers the variables of projects, prioritization criterion, criterion weight, criterion value per project, prioritization index, and relative prioritization index. The following indexes are also used: $i$ represents the number of projects and $j$ represents the number of prioritization criteria.

The projects $\left(\mathrm{P}_{\mathrm{i}}\right)$ of the model represent the potential projects selected to be evaluated as part of the effort to recovering the affected place after the disaster, for example, reconstruction of a bridge that collapsed. The prioritization criteria $\left(\mathrm{C}_{\mathrm{j}}\right)$ represent the parameters, factors, and subfactors defined to be used to prioritize a project. Each prioritization criterion also has a weight (Wj) that measures the importance of this criteria among the others.

$P_{i} \forall i=1, \ldots, N$
$C_{j} \forall j=1, \ldots, M$
$W_{j} \forall j=1, \ldots, M$

Following, for each project and criterion, an importance value $\left(V_{i j}\right)$ is established considering the participant's judgment. In this model, an importance value ranges from 1 to 5 , where 1 is the lowest importance level and 5 the highest importance level. If a committee is used, the consensus value for each project/criterion needs to be agreed before this phase. However, the consensus process is out of the scope of this paper.

$\mathrm{V}_{\mathrm{ij}} \in\{1,2,3,4,5\} \forall \mathrm{i}=1, \ldots, \mathrm{N} ; 1, \ldots, \mathrm{M}$

Finally, a prioritization index $\left(\mathrm{PI}_{\mathrm{i}}\right)$ and a relative prioritization index $\left(\mathrm{RP}_{\mathrm{i}}\right)$ are computed. The prioritization index represents the weighted sum of the importance values, and the relative prioritization index represents the relative value of each prioritization value about the sum of all the prioritization values.

$\mathrm{PI}_{\mathrm{i}}=\sum\left(\mathrm{W}_{\mathrm{j}} \times \mathrm{V}_{\mathrm{ij}}\right) \forall \mathrm{i}=1, \ldots, \mathrm{N} ; 1, \ldots, \mathrm{M}$
$\mathrm{RP}_{\mathrm{i}}=\mathrm{PI}_{\mathrm{i}} / \sum\left(\mathrm{PI}_{\mathrm{i}}\right) \forall \mathrm{i}=1, \ldots, \mathrm{N}$

The accelerated methods component represents the potential accelerated methods that the organization considers to be applicable and the preferability of each of these accelerated methods. The accelerated method $\left(A_{m}\right)$ represents each of the methods. Each accelerated method also has a preference value $\left(\mathrm{AP}_{\mathrm{m}}\right)$. This way, different accelerated methods can be considered for the same project, making different alternatives but one method might be preferred over the other. However, this model does not consider the combination of different accelerated methods into the same project. In this case, the combination of two or more methods needs to be stated as a new accelerated method. The index $\mathrm{m}$ is used to represent the number of accelerated methods.

$A_{m} \forall \mathrm{m}=1, \ldots, \mathrm{K}$

$\mathrm{AP}_{\mathrm{m}} \forall \mathrm{m}=1, \ldots, \mathrm{K}$

The last input component of the model is the projects' alternatives list. This list is a combination of the two previous lists. This list contains the combination of the projects and the accelerated methods suitable for the project. This means that not all of the accelerated methods are suitable for all types of project. The model also considers the option of the traditional method without any acceleration. For each combination of project and accelerated method, an estimated project duration $\left(\mathrm{D}_{\mathrm{im}}\right)$ and an estimated project cost $\left(\mathrm{F}_{\mathrm{im}}\right)$ need to be determined.

Dim $\forall \mathrm{i}=1, \ldots, \mathrm{N} ; \mathrm{m}=1, \ldots, \mathrm{K}$

Fim $\forall i=1, \ldots, N ; m=1, \ldots, K$

Finally, the final solution is constrained by the available fund to recover the affected area. This means those final solutions where the total recovery cost exceeds the available fund will be eliminated from the possible solutions list.

\subsection{Model processing}

The optimization process to obtain the optimal recovery index of the affected area, with the minimum duration and within the available fund uses a combination of Monte Carlo simulation and an optimization method using the OptQuest Engine $\odot$ into the same package. The OptQuest Engine $($ internally combines optimization methods, such as Tabu search, scatter search, integer programming, and neural networks into a single, composite search algorithm.

The simulation runs with a maximum number of trials and until the best solution is found. The idea is to randomly schedule the different project alternatives, without project repetition, and use the accelerated method preference as a probabilistic input for the model. This way, if the model selects a project already scheduled, the model will eliminate this option. Also, with the accelerated method preference as a probabilistic input, the model will give preference to the options with the high preferability. 


\subsection{Model outputs}

The decision-making process will use three outputs extracted from the simulation results: the accumulated recovery index, the total recovery duration, and the total recovery cost. The solutions that do not attend the available fund constraint are eliminated from the list. However, more than one combination of projects can attain the recovery objective. The accumulated recovery index (RI) is expressed by the sum of the relative prioritization index of the projects.

$\mathrm{RI}=\sum\left(\mathrm{RP}_{\mathrm{i}}\right) \forall \mathrm{i}=1, \ldots, \mathrm{N}$

The total recovery duration (TRD) represents the sum of the individual project durations. However, this present model does not consider the potential overlapping of projects. The total recovery cost (TRC) represents the sum of the individual project costs.

$\begin{aligned} \mathrm{TRD} & =\sum\left(\mathrm{D}_{\text {im }}\right) \forall \mathrm{i}=1, \ldots, \mathrm{N} ; \mathrm{m}=1, \ldots, \mathrm{K} \\ \mathrm{TRC} & =\sum\left(\mathrm{F}_{\text {im }}\right) \forall \mathrm{i}=1, \ldots, \mathrm{N} ; \mathrm{m}=1, \ldots, \mathrm{K}\end{aligned}$

Therefore, considering the objective to find the optimum combination of projects, while maximizing the accumulated recovery index and minimizing the total recovery duration, the proposed conceptual model can be represented as:

$\max \mathrm{RI}=\sum\left(\mathrm{RP}_{\mathrm{i}}\right) \forall \mathrm{i}=1, \ldots, \mathrm{N}$

$\min \mathrm{TRD}=\sum\left(\mathrm{D}_{\text {im }}\right) \forall \mathrm{i}=1, \ldots, \mathrm{N} ; \mathrm{m}=1, \ldots, \mathrm{K}$

subject to $\sum\left(\mathrm{F}_{\mathrm{im}}\right) \leq \mathrm{B}$

\section{Model demonstration}

A demonstration of the model was created using synthetic data. The hypothetical scenario included 5 (five) projects, 5 (five) prioritization criteria, 4 (four) acceleration methods plus the option without acceleration. Therefore, a total of 25 different alternatives were used for prioritization. Each alternative had also a cost and a duration associated. Additionally, the model was subjected to 3 (three) constraints: total investment less than $\$ 25,000,000$, recovery index equal to or higher than $80 \%$, and no repetition of projects. The goal was to find the minimum duration, sequencing 5 possible projects. The model was set to run using Latin Hypercube and to stop running after 100 trials or when the progress maximum change reached $0.05 \%$. The run stopped after reach the maximum number of trials and one best trial was found. The best result is showed in Table 1.

The best result can be achieved with only one project being accelerated (project 4) and the other four projects without acceleration (projects 3, 1, 5, and 2), attaining a total duration of 2325 days, a total investment of $\$$ $24,630,000$, and an accumulated recovery index of 1.00 in the end. This was the case that attended all the conditions of the problem. If constraints are relaxed, more alternatives can be part of the solution. For example, if the limit of the total investment increases to
$\$ 28,000,000$, more 5 (five) project combinations can be part in the solution universe.

Table 1. Best trial result.

\begin{tabular}{|c|c|c|c|}
\hline $\begin{array}{c}\text { Project } \\
\text { sequence (ID, } \\
\text { Project, } \\
\text { accelerated } \\
\text { method) }\end{array}$ & $\begin{array}{c}\text { Project } \\
\text { duration } \\
\text { (days) }\end{array}$ & $\begin{array}{c}\text { Project cost } \\
\text { (\$) }\end{array}$ & $\begin{array}{c}\text { Recovery } \\
\text { index }\end{array}$ \\
\hline $\begin{array}{c}\text { 17- Project 4, } \\
\text { ABC }\end{array}$ & 306 & $\$ 4,440,000.00$ & $0.17(0.17)$ \\
\hline $\begin{array}{c}\text { 11- Project 3, } \\
\text { no acceleration }\end{array}$ & 494 & $\$ 4,940,000.00$ & $0.18(0.35)$ \\
\hline $\begin{array}{c}\text { 1- Project 1, no } \\
\text { acceleration }\end{array}$ & 619 & $\$ 6,190,000.00$ & $0.13(0.48)$ \\
\hline $\begin{array}{c}\text { 21- Project 5, } \\
\text { no acceleration }\end{array}$ & 577 & $\$ 5,770,000.00$ & $0.25(0.73)$ \\
\hline $\begin{array}{c}\text { 6- Project 2, no } \\
\text { acceleration }\end{array}$ & 329 & $\$ 3,290,000.00$ & $0.27(1.00)$ \\
\hline Total & 2325 & $\$ 24,630,000$ & $1.0(100 \%)$ \\
\hline
\end{tabular}

\section{Conclusions}

This paper performed a literature review and investigated the current practices to develop a conceptual model for prioritizing needs for accelerated construction after natural disaster events. The research focused on the transportation infrastructure components typically affected by hurricanes and flooding which commonly affect Region 6. The proposed conceptual model is the first phase of this research, and in the next phase, we will continue to collect expert knowledge through survey and interview to quantify the identified decision-making criteria and to validate the proposed model. This research will eventually benefit resiliency and emergency response planners from state DOTs by guiding identify and prioritize needs for accelerated construction after disaster events.

\section{References}

1. Ballard, M. (2016). Historic Flooding in Louisiana Declared a Federal Disaster. Tribune News Service. Governing the States and Localities. Retrieved from http://www.governing.com/topics/transportationinfrastructure/tns-louisiana-flooding-beledwards.html

2. Stein, N., Weisbrod, G., Sieber, M., National Cooperative Highway Research, P., National Cooperative Highway Research Program Synthesis, P., Synthesis, P., National Academies of Sciences, E. a. M. (2018). Investment Prioritization Methods for Low-Volume Roads. Washington, D.C.: Transportation Research Board.

3. Chen, Y.-W., and Tzeng, G.-H. (1999). A Fuzzy Multi-Objective Model for Reconstructing the Post-Quake Road-network by Genetic Algorithm. International Journal of Fuzzy Systems, 1(2), 11.

4. Zamanifar, M., and Seyedhoseyni, S.M. (2017). Recovery planning model for roadways network 
after natural hazards. Natural Hazards, 87(2), 699716. doi:10.1007/s11069-017-2788-4

5. Orabi, W., El-Rayes, K., Senouci, A.B., AlDerham, H. (2009). Optimizing postdisaster reconstruction planning for damaged transportation networks. 135(10), 1039-1048.

6. El-Anwar, O., Ye, J., and Orabi, W. (2013). Efficient Analysis and Optimization of Reconstruction Plans for Damaged Transportation Networks Following Disasters. In Computing in Civil Engineering, 354-362.

7. El-Anwar, O., Ye, J., and Orabi, W. (2016). Efficient Optimization of Post-Disaster Reconstruction of Transportation Networks. Journal of Computing in Civil Engineering, 30(3), $04015047 . \quad$ doi:10.1061/(ASCE)CP.19435487.0000503

8. Orugbo, E.E., Alkali, B.M., DeSilva, A., and Harrison, D.K. (2015). RCM and AHP Hybrid Model for Road Network Maintenance Prioritization. The Baltic Journal of Road and Bridge Engineering, 10(2), 182-190. doi:10.3846/bjrbe.2015.23

9. Arif, F., Bayraktar, M.E., and Chowdhury, A.G. (2016). Decision Support Framework for Infrastructure Maintenance Investment Decision Making. Journal of Management in Engineering, 32(1), 04015030. doi:10.1061/(ASCE)ME.19435479.0000372 